\title{
Heligmosomoides neopolygyrus Asakawa \& Ohbayashi, 1986, a cryptic Asian nematode infecting the striped field mouse Apodemus agrarius in Central Europe
}

\author{
Grzegorz Zaleśny ${ }^{1}$, Joanna Hildebrand ${ }^{2}$, Anna Paziewska-Harris ${ }^{3}$, Jerzy M Behnke ${ }^{4}$ and Philip D Harris $5^{5^{*}}$
}

\begin{abstract}
Background: Heligmosomoides polygyrus is a widespread gastro-intestinal nematode infecting wild Apodemus (wood mice) throughout Europe. Using molecular and morphological evidence, we review the status of Heligmosomoides from Apodemus agrarius in Poland previously considered to be an outlying clade of H. polygyrus, to further resolve the status of the laboratory model species, H. bakeri.

Methods: Morphological analysis of the male bursa and the synlophe, and molecular analyses of concatenated nuclear (28S rDNA, ITS1 and ITS2) and mitochondrial (CO1 and cytb) genes, of Heligmosomoides collected from Apodemus agrarius from two sites in Poland and comparison with related heligmosomids from voles and mice in Eurasia.

Results: Heligmosomoides neopolygyrus, a heligmosomid nematode from Apodemus species from China and Japan, is recognised for the first time in western Europe infecting Apodemus agrarius in Poland. It can be distinguished from $\mathrm{H}$. polygyrus by the filiform externo-dorsal rays of the male copulatory bursa and the small, equally distributed longitudinal crêtes on the body. Specimens from A. agrarius are 20\% different at ribosomal (ITS1 and ITS2) nuclear loci, and 10\% different at the mitochondrial cytb locus from H. polygyrus, and in phylogenetic analyses group with the vole-infecting genus Heligmosomum.

Conclusions: Despite morphological similarity, H. neopolygyrus is only distantly related to H. polygyrus from western European Apodemus, and may be more closely related to vole-infecting taxa. It was brought into Europe by the recent rapid migration of the host mice. Inclusion of $\mathrm{H}$. neopolygyrus in phylogenies makes it clear that Heligmosomoides is paraphyletic, with the pika-infecting Ohbayashinema and the vole-infecting Heligmosomum nesting within it. Clarification of the European status of $\mathrm{H}$. neopolygyrus also allows $\mathrm{H}$. bakeri, the laboratory model species, to be seen as a terminal sister clade to $H$. polygyrus, rather than as an internal clade of the latter taxon.
\end{abstract}

Keywords: Gastro-intestinal nematode, Phylogeography, Rodent, Post-glacial expansion, Rodent, Helminth biodiversity

\section{Background}

Gastro-intestinal (GI) nematodes of the genus Heligmosomoides are well known parasites of wild rodents, which through their strong immunosuppressive effect $[1,2]$ may be considered architects of helminth and pathogen communities in these hosts [1]. The laboratory model, H. bakeri infecting Mus, is one of the most intensively studied GI

\footnotetext{
* Correspondence: p.d.harris@nhm.uio.no

${ }^{5}$ Natural History Museum, University of Oslo, P.O. Box 1172, N-0562 Oslo, Norway Full list of author information is available at the end of the article
}

nematodes, with detailed accounts of its immunological and molecular interactions with the host $[3,4]$. Nevertheless, knowledge of other species in the genus is highly confused, and even the independent specific status of $H$. bakeri, as distinct from the Apodemus-infecting $H$. polygyrus, is controversial and bitterly debated [5-7]. A problem with the taxonomy of Heligmosomoides concerns the poor standards of description and lack of type material for older species such as $H$. polygyrus, originally described as Strongylus polygyrus by Dujardin [8]. This problem was exacerbated by the finding that, based on comparison of a 
fragment of the cytochrome b (cytb) mitochondrial gene, $H$. polygyrus exists in its wild hosts as numerous distinct and geographically discrete clades [9-11], which may or may not represent cryptic species. Indeed, Cable et al. [5] concluded that the problem lay not with our understanding of the laboratory model $H$. bakeri, but with our lack of knowledge of the broader $H$. polygyrus clade. Since then, Behnke \& Harris [6] have highlighted the similarity at molecular loci between $H$. polygyrus corsicum, a taxon infecting M. musculus on Corsica and Apodemus spp. in Asia Minor [10,11], and usually considered a subspecies of $H$. polygyrus, and $H$. bakeri, and it is possible that these two forms are part of the same species. If $H$. polygyrus corsicum and $H$. bakeri can be shown to form an internal clade within $H$. polygyrus, then there can be little support for considering them as distinct species. On the other hand, if these taxa represent distinct terminal clades, then the hypothesis that they are independent species would continue to deserve consideration. Scrutiny of the phylogeny of Nieberding et al. [10] does indeed reveal an additional $H$. polygyrus clade (their clade 4 ) which lies outwith the entire sampled $H$. polygyrus $/ H$. polygyrus corsicum clade. This clade, from Russia and Poland, predominantly from the the striped field mouse Apodemus agrarius, was considered evidence for a northern glacial refugium for $H$. polygyrus in Central Europe [10].

This clade presents an important test of the null hypothesis that $H$. bakeri and $H$. polygyrus are part of the same taxon, and for this reason we have undertaken the present study of Heligmosomoides from A. agrarius in central Europe. The results make it clear that this clade is not identical to $H$. polygyrus, but can be linked instead to $H$. neopolygyrus, a species previously known only from Asia east of the Urals. This species not only sheds light on the evolution of Heligmosomoides as a whole, but also appears to represent another example of the A. agrarius parasitofauna imported into Europe with the natural westward migration of its host.

\section{Methods}

\section{Collection of worms}

Heligmosomoides were collected from $A$. agrarius live-trapped near Wrocław and Gdańsk in Poland. Comparative material of $H$. polygyrus was collected from A. flavicollis from these sites, and from A. sylvaticus from Norway, the UK and Ireland. H. glareoli was collected from bank voles (Myodes glareolus) from Scotland and the island of Anglesey (Wales), and representatives of Heligmosomum mixtum were collected from the same host from Eastern Poland (same site as described in Cable et al. [5]), and from Wrocław. H. costellatum from Microtus arvalis was also available from the latter site. Material of $H$. polygyrus corsicum, from the same collections used in a study by Nieberding et al. $[10,11]$ was also examined. $H$. bakeri was obtained from the Nottingham laboratory colony of this species [5]. Full details of collection sites are given in Table 1. Animals were euthanised and dissected within a few hours of collection and worms found collected into $80 \%$ ethanol for long-term storage at -20 or $-80^{\circ} \mathrm{C}$.

Rodents were collected according to the legal and ethical guidelines current in the countries where they were sampled.

\section{Morphological methods}

The synlophes of $H$. polygyrus and $H$. neopolygyrus were studied using $2 \mu \mathrm{m}$ transverse sections of methacrylateembedded (Sigma) females stained with $0.1 \%$ methylene blue. To determine the 3-dimensional structure of the synlophe, specimens were also stained in $0.1 \%$ silver nitrate following the method of Khrustalev and Hoberg [12], modified by developing the silver stain by exposure to bright daylight for 5 minutes. For study of the caudal bursa of males, worms were cut just anterior to the spicules and extracted in CellLytic bacterial lysis reagent (Sigma) for up to $48 \mathrm{~h}$ before mounting in lactophenol for photography. Phase contrast photography was performed using a Leica DM600b with Leica DC500 camera. Voucher specimens of $H$. polygyrus and $H$. neopolygyrus have been deposited in the Natural History Museum (NHM) Oslo (accession numbers NHMO C5921-C5923), NHM London (accession numbers NHMUK 2014.2.14.1, NHMUK.2014.2.14.2-7, NHMUK.2014.2.14.8-10) and the NHM of Wroclaw University. Representative DNA samples are deposited in NHM Oslo (accession numbers NHMO NEM 0001-0019).

\section{Molecular methods}

A total of three specimens from $A$. agrarius (2 from Wrocław, one from Gdańsk) were used for molecular analysis. As the other taxa all had representative sequences within Genbank, only single specimens from each site were sequenced. DNA was extracted using the E.Z.N.A. Tissue DNA Kit (Omega Bio-Tek, USA), and amplified using PCR specific for 3 nuclear markers (internal transcribed spacers 1 and 2 [ITS1, ITS2], and a fragment of $28 \mathrm{~S}$ rDNA) and 2 mitochondrial markers (fragments of genes encoding cytochrome oxidase I $[C O 1]$ and cytochrome $\mathrm{b}[c y t b])$. Primer sequences were drawn from the literature [5,9,13-15] (for detailed information see Table 2). PCR conditions included initial denaturation in $95^{\circ} \mathrm{C}$ for $5 \mathrm{~min}$, followed by 35 cycles: $45 \mathrm{~s}$ denaturation $\left(95^{\circ} \mathrm{C}\right), 30 \mathrm{~s}$ annealing $\left(50^{\circ} \mathrm{C}\right.$ for $\mathrm{CO} 1,52^{\circ} \mathrm{C}$ for $c y t b, 54^{\circ} \mathrm{C}$ for $28 \mathrm{~S}$ rDNA and $60^{\circ} \mathrm{C}$ for ITS1 and ITS2), $30 \mathrm{~s}$ elongation $\left(72^{\circ}\right)$, and a $5 \mathrm{~min}$ step of final elongation $\left(72^{\circ} \mathrm{C}\right)$. PCR products were sequenced using the same primer pairs, and chromatograms inspected visually for ambiguities. Alignments were produced using ClustalX within the Mega 5.0 package [16] followed by 
Table 1 Material sequenced during this study

\begin{tabular}{|c|c|c|c|c|c|}
\hline Parasite & Host & Locality & Country & Latitude & Longitude \\
\hline H. neopolygyrus & A. agrarius & Mokry Dwór, Wrocław & Poland & $51^{\circ} 04^{\prime} 57 \mathrm{~N}$ & $17^{\circ} 06^{\prime} 13 \mathrm{E}$ \\
\hline H. neopolygyrus & A. agrarius & Gdańsk & Poland & $54^{\circ} 21^{\prime} 19 \mathrm{~N}$ & $18^{\circ} 48^{\prime} 20 \mathrm{E}$ \\
\hline H. polygyrus & A. sylvaticus & Jar & Norway & $59^{\circ} 55^{\prime} 15 \mathrm{~N}$ & $10^{\circ} 37^{\prime} 46 \mathrm{E}$ \\
\hline H. polygyrus & A. sylvaticus & Weybourne Lodge Camp, Norfolk & UK & $52^{\circ} 55^{\prime} 43 \mathrm{~N}$ & $1^{\circ} 09^{\prime} 11 \mathrm{E}$ \\
\hline H. polygyrus & A. sylvaticus & Kildare & Eire & $53^{\circ} 09^{\prime} 45 \mathrm{~N}$ & $6^{\circ} 55^{\prime} 07 \mathrm{~W}$ \\
\hline H. polygyrus & A. flavicollis & Mokry Dwór, Wrocław & Poland & $51^{\circ} 04^{\prime} 57 \mathrm{~N}$ & $17^{\circ} 06^{\prime} 13 \mathrm{E}$ \\
\hline H. polygyrus corsicum & A. mystacinus & Trabzon-Sumela Road & Turkey & $40^{\circ} 50^{\prime} 00 \mathrm{~N}$ & $39^{\circ} 42^{\prime} 00 \mathrm{E}$ \\
\hline H. glareoli & My. glareolus & Moredun Institute Edinburgh & UK & $55^{\circ} 54^{\prime} 53 \mathrm{~N}$ & $3^{\circ} 07^{\prime} 26 \mathrm{E}$ \\
\hline H. bakeri & Mus musculus & Nottingham laboratory colony & & & \\
\hline H. glareoli & My. glareolus & Anglesey & UK & $53^{\circ} 10^{\prime} 55 \mathrm{~N}$ & $4^{\circ} 10^{\prime} 40 \mathrm{~W}$ \\
\hline H. mixtum & My. glareolus & Urwitałt forest, & Poland & $53^{\circ} 47^{\prime} 51 \mathrm{~N}$ & $21^{\circ} 39^{\prime} 07 \mathrm{E}$ \\
\hline H. mixtum & My. glareolus & Mokry Dwór, Wrocław & Poland & $51^{\circ} 04^{\prime} 57 \mathrm{~N}$ & $17^{\circ} 06^{\prime} 13 \mathrm{E}$ \\
\hline H. costellatum & Mi. arvalis & Mokry Dwór, Wrocław & Poland & $51^{\circ} 04^{\prime} 57 \mathrm{~N}$ & $17^{\circ} 06^{\prime} 13 \mathrm{E}$ \\
\hline
\end{tabular}

visual inspection. Phylogenetic analysis was conducted using a Maximum Likelihood algorithm implemented in RaxML vs 8.0 [17] via the CIPRES Science Gateway portal [18]. Nuclear ribosomal analysis was conducted on concatenated sequences (1704 bp) partitioned into 28S, ITS1, 5.8S and ITS2 genes, and included Ohbayashinema erbaevae, previously described as a representative of a sister genus to Heligmosomoides and Heligmosomum [19,20], $H$. kurilensis kobayashii and a variety of $H$. polygyrus sequences drawn from GenBank (Table 3). The concatenated alignment included sequences represented at only one or two of the 4 loci included in the alignment, but overall each nucleotide site was represented by between $66 \%$ (28S, central region of $5.8 \mathrm{~S}$ ) and $100 \%$ (central regions of ITS1 and ITS2) of the aligned sequences. After computation of the best phylogeny (100 bootstrap replicates), identical and closely similar sequences were removed iteratively to include $H$. polygyrus diversity without over-representing this taxon in the phylogeny.
For CO1 and cytb a concatenated alignment (1411 bp) was produced including $H$. polygyrus sequences from each of the major mitochondrial clades identified previously [9-11]. Coverage in this case included 97\% of all nucleotide positions within $c y t b$ and $42 \%$ of all nucleotide positions within CO1. Eleven isolates (35\% of the total), including examples of all major clades, were represented at both $c y t b$ and $C O 1$ loci. For nuclear ribosomal loci, the chosen outgroup was Nematodirus battus. For analysis of mitochondrial markers, Trichostrongylus axei was used as outgroup. To confirm the results obtained using the concatenated nuclear alignment, homology modelling of ITS2 was undertaken using the ITS2 database (http://its2. bioapps.biozentrum.uni-wuerzburg.de/; [21]) with the secondary structure for Trichostrongylus ITS2 originally presented by Chilton et al. [22] in order to optimise the alignment (see Additional file 1). This optimised ITS2 alignment was analysed alone (Additional file 1) and also incorporated into the concatenated nuclear alignment.

Table 2 Primer pairs used in the study (F- forward, R- reversed)

\begin{tabular}{|c|c|c|c|}
\hline Amplified gene & Primers $\left(5^{\prime} \rightarrow 3^{\prime}\right)$ & Amplified fragment length (bp) & Reference \\
\hline \multirow[t]{2}{*}{$\mathrm{CO}$} & F: GGTCAACAAATCATAAAGATATTGG & 559 & [5] \\
\hline & R: TAAACTTCAGGGTGACCAAAAAATCA & & \\
\hline \multirow[t]{2}{*}{ cytb } & F: GRAATTITGGTAGTATRTTRG & 616 & [9] \\
\hline & R: AGMACGYAAAATWGYAWAAGC & & \\
\hline \multirow[t]{2}{*}{ ITS1 } & F: TTGAACCGGGTAAAGTCGT & $387-423$ & {$[5,13]$} \\
\hline & R: ACAACCCTGAACCAGACGTG & & \\
\hline \multirow[t]{2}{*}{ ITS2 } & F: ACGTCTGGTTCAGGGTTGT & $276-306$ & {$[5,14]$} \\
\hline & R: TTAGTTCTITCCTCCGCT & & \\
\hline \multirow[t]{2}{*}{$28 \mathrm{~S}$ rDNA } & F: ACCCGCTGAATTTAAGCAT & 619 & {$[15]$} \\
\hline & R: TCCGTGTTTCAAGACGG & & \\
\hline
\end{tabular}


Table 3 Sequences of Heligmosomidae used in phylogenetic analysis

\begin{tabular}{|c|c|c|c|c|c|c|c|}
\hline Parasite and host & Locality & CO1 & cytb & ITS1 & ITS2 & $28 \mathrm{~S}$ rDNA & Source \\
\hline H. neopolygyrus, A. agrarius & Gdańsk, Poland & KF765455 & KF765451 & KF765458 & KF765463 & KF765468 & This study \\
\hline H. neopolygyrus, A. agrarius & Wrocław, Poland & KJ994541 & KJ994551 & & & & This study \\
\hline H. polygyrus, A. flavicollis & Wrocław, Poland & KF765456 & KF765452 & KF765459 & KF765464 & KF765469 & This study \\
\hline H. polygyrus, A. sylvaticus & Jar, Norway & KJ994543 & KJ994553 & KJ994557 & KJ994560 & Identical to KF765469 & This study \\
\hline H. polygyrus, A. sylvaticus & Kildare, Eire & KJ994542 & KJ994548 & & & & This study \\
\hline H.p. polygyrus, A.sylvaticus & Norfolk & KJ994544 & KJ994549 & KJ994555 & KJ994558 & Identical to KF765469 & This study \\
\hline H. p.polygyrus, A. sylvaticus & 98911 It, Italy & & & AM409071 & AM409087 & ND & 9 \\
\hline H. p.polygyrus, A. sylvaticus & Slovakia 11112Sa & ND & AM408297 & & & & 10 \\
\hline H.p. polygyrus, A. sylvaticus & France $10192 \mathrm{~F}$ & ND & AM408288 & & & & 10 \\
\hline H.p.polygyrus, A.sylvaticus & Pancas, Portugal & KJ994545 & KJ994550 & & & & This study \\
\hline H. p.polygyrus, A. sylvaticus & Minorca 7672Mi & ND & AJ971171 & & & & 11 \\
\hline H. bakeri, M. musculus & Nottingham strain & DQ408627 & KJ994554 & DQ408624 & DQ408624 & AM039747 & 5 \\
\hline H. bakeri, M. musculus & Maizels genome project ${ }^{3}$ & Contig 252200 & Contig 252200 & & & & \\
\hline H.p. corsicum, A. mystacinus ${ }^{1}$ & Turkey & & & AM409074 & AM409090 & ND & 11 \\
\hline H.p. corsicum, A. mystacinus ${ }^{1}$ & Turkey & KJ994540 & KJ994547 & KJ994556 & KJ994559 & KJ994539 & This study \\
\hline H.p. corsicum, M. musculus ${ }^{1}$ & Corsica 9702 F3 & ND & AJ971230 & & & & 11 \\
\hline H. glareoli, M. glareolus & Edinburgh, Scotland UK & KF765457 & KF765453 & KF765460 & KF765465 & KF765470 & This study \\
\hline H. glareoli, M. glareolus & Urwitałt Forest, Poland & DQ408634 & ND & & & & 5 \\
\hline H. glareoli, M. glareolus & Anglesey, Wales, UK & KJ994546 & KJ94552 & & & & This study \\
\hline H. kurilensis kobayashii, A. speciosus & Japan & ND & AJ971146 & AM409077 & AM409093 & ND & 10 \\
\hline H. mixtum, M. glareolus & Wrocław, Poland & ND & KF765454 & KF765461 & KF765466 & KF765471 & This study \\
\hline H. mixtum, M. glareolus & Mazury, Poland & DQ408635 & ND & & & & 5 \\
\hline H. mixtum, M. glareolus & Spain 1340 & ND & AJ971145 & & & & 11 \\
\hline H.costellatum, M. arvalis & Wrocław, Poland & & & KF765462 & KF765467 & KF765472 & This study \\
\hline O. erbaevae, O. daurica & Russia, Bouriatia & & & AY332647 & AY333381 & AF210038, AF210014, AF209991 & 20 \\
\hline
\end{tabular}

${ }^{1}$ This subspecies was originally described from Mus musculus domesticus from Corsica; however, ITS1 and ITS2 sequences are available only for parasites collected from Apodemus mystacinus from Turkey and linked to specimens from Corsica by identity of their cytb sequences ([11]).

Sequences for H. p. polygyrus Jar and H. bakeri cytb are truncated relative to the other isolates.

${ }^{3}$ Sequence obtained through 959 Nematode Genome project (http://www.nematodes.org/nematodegenomes/index.php/959_Nematode_Genomes). ND indicates sequence not available for inclusion in the

concatenated alignments (mitochondrial or nuclear). A blank cell indicates a taxon not included in the relevant alignment. 


\section{Results}

\section{Morphological comparison}

Worms from $A$. agrarius were moderately large (females up to $15 \mathrm{~mm}$ ), reddish, slender and strongly coiled, with a habitus similar to that of $H$. polygyrus. The synlophe consisted of 18-24 longitudinal (not diagonal or partially diagonal as in Heligmosomum) crêtes, diagnostic for Heligmosomoides as re-established by Durette-Desset $[23,24]$. In cross-section, a clear distinction between the crêtes of the worms from $A$. agrarius and those of $H$. polygyrus was noted (Figure 1 ). In $H$. polygyrus, the crêtes were smallest in the dorsal right-hand quadrant of the worm and increased in size to the ventral left-hand quadrant, where the largest crête is located (Figure 1A), exactly as described by Durette-Desset [25]. The size of the crêtes increases gradually and monotonically from the smallest to the largest. In worms from A. agrarius, by contrast, there was no gradual increase in the size of the crêtes from dorsal right quadrant to ventral left quadrant, and instead the crêtes were more or less the same small size around the entire circumference of the worm (Figure 1B). The long filiform spicules of the worms from $A$. agrarius were similar to those from $H$. polygyrus and $H$. bakeri, with a total length of c. $700 \mu \mathrm{m}$. The copulatory bursa of the male worms from $A$. agrarius was asymmetrical, with the right lobe c. 30\% larger than the left lobe. The arrangement of the rays was similar to that of $H$. polygyrus, with one notable difference; the externo-dorsal rays of the bursa in these worms were filiform (Figure 1C), and lacked the swollen base characteristic of $H$. polygyrus (Figure 1D).

\section{Phylogenetic analysis}

Where comparison with accessions in Genbank was possible, sequences from $H$. polygyrus, $H$. glareoli and $H$. bakeri were similar or identical to existing curated sequences and merely extended geographical coverage, and in some cases the number of loci sequenced. Material from Myodes glareolus from Wrocław identified morphologically as $H$. mixtum was identical with sequences in Genbank from M. glareolus in NE Poland (collected and sequenced by Cable et al. [5] ) and with a sequence from Genbank (AJ971145) labelled 'Heligmosomoides costellatum' (sic) and deposited by Nieberding et al. [10]. Our worms were identified morphologically according to the criteria outlined in Tenora et al. [26], and moreover the Spanish $H$. costellatum sequence is recorded as collected from Myodes glareolus, the nominal host of $H$. mixtum. We consider this, therefore, to be an erroneously labelled example of $H$. mixtum, and our own $H$. costellatum sequences to be the first of this species to be deposited in Genbank.

The Heligmosomoides species from $A$. agrarius differed considerably at all sequenced loci from $H$. polygyrus. Across the 605 base $28 \mathrm{~S}$ gene fragment, the worms from $A$. agrarius differed from $H$. polygyrus at 3 bases $(0.5 \%)$, when the maximum difference noted (between $H$. glareoli and $H$. polygyrus) was 10 bases (1.6\%). Across the
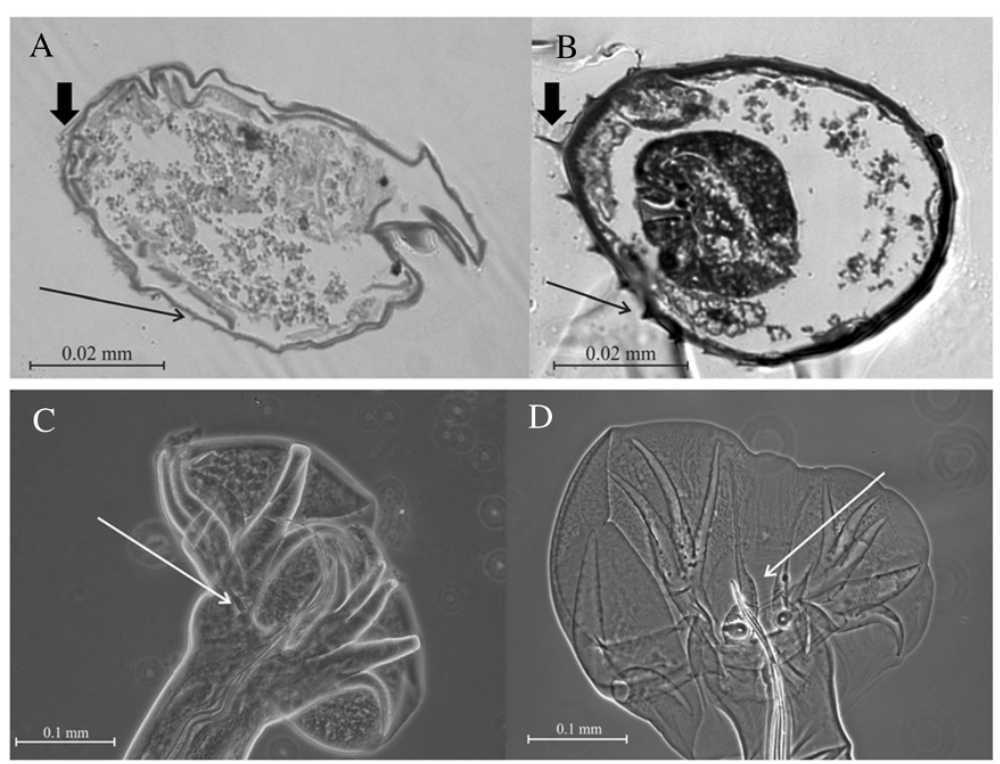

Figure 1 The morphology of $\boldsymbol{H}$. polygyrus and $\boldsymbol{H}$. neopolygyrus. A) a cross section through the mid-region of $H$. polygyrus female; B) a cross section through the mid-region of $\mathrm{H}$. neopolygyrus female; In both cases, the worm is oriented with the head away from the viewer, with the dorsal surface at the top of the image. Slender black arrows indicate the ventral crête of the respective worms; the short black arrows indicate the ventral left-hand quadrant where the crête is largest in H. polygyrus but not in H. neopolygyrus. C) bursa of H. neopolygyrus; D) bursa of H. polygyrus; White arrows indicate the externo-dorsal rays, showing the enlarged base in $\mathrm{H}$. polygyrus but the filiform ray present in $\mathrm{H}$. neopolygyrus. 
combined ITS1/ITS2 alignment, the pairwise differences between the worms from $A$. agrarius and $H$. polygyrus was c. $5 \%$, and even within the modelled 213 bp alignment of the stems in ITS2 (Additional file 1), there were 10 base pair differences (4.6\%). The sequenced isolates of the worms from $A$. agrarius were identical at these nuclear loci. Across the 616 base pair cytb alignment, there were 27 base pair differences (4.4\%), which were diagnostic of the worms from $A$. agrarius relative to $H$. polygyrus (other variable sites were also polymorphic within $H$. polygyrus), and within the 559 cox 1 alignment, there were $40(7.1 \%)$ base changes. The differences between these worms and $H$. polygyrus are therefore substantial at all sequenced loci. A single base difference (T269G) was noted between the two isolates (from Wrocław and Gdańsk) at $c o x 1$, while their $c y t b$ sequences were identical. A group of cytb sequences in Genbank (AM408290, AM408307 - AM408312, all from Poland) were also almost identical to the sequences from the worms from $A$. agrarius, differing by up to 3 bases $(0.5 \%)$ while a further sequence (AM408303) from worms collected from A. uralensis in Russia east of the Urals, differs from these sequences at 6 bases $(0.9 \%)$.

The worms from $A$. agrarius clustered consistently with the genus Heligmosomum at both concatenated nuclear and mitochondrial loci (Figure 2A,B). Molecular analysis of the concatenated nuclear markers (Figure 2A) recovered two strongly supported clades within the Heligmosomidae, with Ohbayashinema erbaevi, H. glareoli and H. kurilensis kobayashii failing to cluster with either. One of the strongly supported clades (88\% bootstrap support) linked the worms from A. agrarius with Heligmosomum costellatum and $H$. mixtum. The other strongly supported clade (92\% support) linked Heligmosomoides polygyrus with $H$. polygyrus corsicum and $H$. bakeri. $H$. bakeri showed higher sequence similarity to $H$. polygyrus corsicum than to $H$. polygyrus polygyrus, which formed a sister group to the $H$. polygyrus corsicum/H. bakeri clade. Support for these two terminal clades was 96\% and 91\% respectively. $H$. kurilensis kobayashii was recovered with the $H . p$. polygyrus $+H$. p. corsicum $/ H$. bakeri clade, but bootstrap support for this association was weak (66\%). Ohbayashinema erbaevae was recovered as an unresolved polytomy within the clade including $H$. polygyrus, $H$. bakeri, H. kurilensis kobayashii and Heligmosomum, while the position of $H$. glareoli was unresolved but lay outside this main Heligmosomoides clade. Using a more conservative alignment including a subset of 216 bases unambiguously identified as lying within base-paired stem regions of ITS2, based on homology modelling with the Trichostrongylus/Camelostrongylus structure of Chilton et al. [22] (Additional file 1), the clade including $H$. polygyrus, $H$. bakeri and $H$. polygyrus corsicum, but excluding the worms from A. agrarius, was recovered in $96 \%$ of bootstrap replicates, while the worms from $A$. agrarius clustered with $H$. mixtum in $70 \%$ of bootstrap replicates. No analysis revealed an association between the worms from $A$. agrarius and $H$. polygyrus.

Analysis of concatenated mitochondrial markers also failed to recover a clade grouping the worms from $A$. agrarius with $H$. polygyrus to the exclusion of other Heligmosomoides species (Figure 2B). Four well supported clades were recovered using the concatenated alignment, although the relative relationship of these clades to each other could not be discerned. The first well supported clade (bootstrap support 98\%) included Heligmosomum and the worms from Apodemus agrarius. The other well
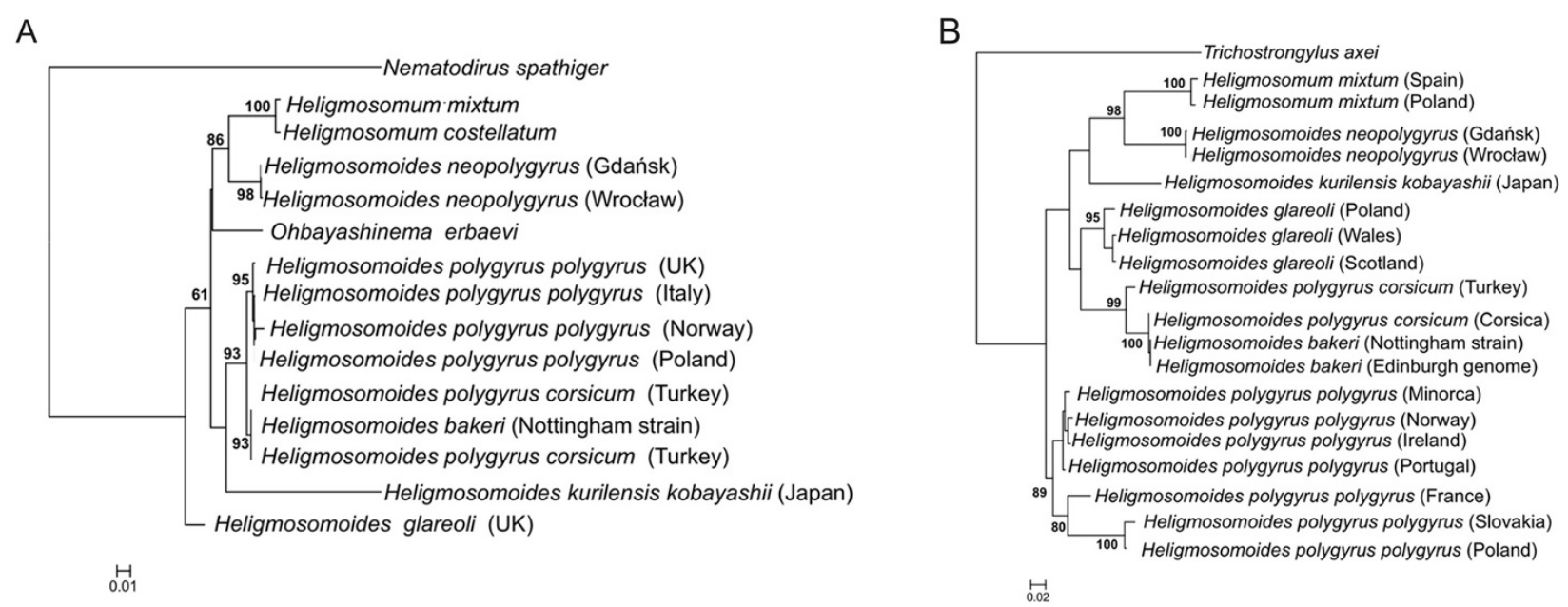

Figure 2 Phylogenetic analysis of the representatives of the Heligmosomidae. A) concatenated nuclear (28S rDNA, ITS1, 5.8S and ITS2) loci, B) concatenated mitochondrial loci (partial CO1 and cytb genes) The analysis was performed using the Maximum Likelihood algorithm within the RaxML package implemented via the CIPRES gateway. Bootstrap support calculated on basis of 500 replicates (only values above $60 \%$ shown). 
supported groups were $H$. glareoli (bootstrap support 95\%), H. polygyrus corsicum/H. bakeri (bootstrap support 99\%) and H. p. polygyrus (bootstrap support $89 \%$ ).

\section{Discussion}

Heligmosomoides collected from A. agrarius in Poland appeared at first sight to belong to $H$. polygyrus, the common species recorded from Apodemus throughout Europe. The worms were red, slender and strongly coiled, with longitudinally orientated crêtes, typical of the genus as re-erected by Durette-Desset $[23,24]$. However, examination at two concatenated mitochondrial (cytb and CO1) and four concatenated nuclear (28S rDNA, ITS1, 5.8S rDNA and ITS2) loci make it clear that this worm is quite distinct to $H$. polygyrus, and cannot be regarded as the same species. Indeed, this taxon does not even form a sister clade to $H$. polygyrus, and clusters rather with the genus Heligmosomum (H. mixtum and $H$. costellatum). The cytb sequences obtained in the present work link this taxon unambiguously with specimens from $A$. agrarius collected by Nieberding et al. [10] from Poland (Lublin), previously misidentified because of lack of nuclear data as $H$. polygyrus. The $c y t b$ sequences of the Nieberding Polish material are also very similar to that (AM408303) of a specimen collected from A. uralensis in the region of Novosibirsk [10], suggesting that this taxon is widespread in eastern Europe and western Asia.

Four Heligmosomoides species have been described from Apodemus east of the Urals, and could be linked to the Nieberding Siberian $c y t b$ sequence, and therefore to the worms collected from A. agrarius. H. kurilensis was described from $A$. speciosus from the Kuril Islands but the male has a spicule of greater than $2 \mathrm{~mm}$ in length, compared to the $700 \mu \mathrm{m}$ spicules for worms from $A$. agrarius. This species is not identical to the material considered in the present work, a view corroborated by inspection of sequences for this species deposited in Genbank. The second species from Apodemus in Japan, H. desportesi Chabaud, Rausch and Desset, 1963, is less well documented, but at least according to the habitus photographs presented by Asakawa and Ohbayashi [27], is a much more robust nematode, with a greater diameter which does not overlap with that of $H$. polygyrus, and with a symmetrical caudal bursa. This also does not appear to be identical to material collected in the present work, although there is some doubt because $H$. desportesi as redescribed by Asakawa and Ohbayashi [27] does not conform to the original description [28], and it has been suggested [27] that this material might be a synonym of $H$. polygyrus. No molecular sequences are available for this species. The third species from Japanese Apodemus seems a much stronger candidate for comparison with the worms from Polish A. agrarius.
This is $H$. neopolygyrus [27], collected originally from A. peninsulae in Hokkaido. This has the same habitus as $H$. polygyrus, but the most convincing point of comparison concerns the slender, filiform externo-dorsal rays of the male bursa. This was noted as a specific character of $H$. neopolygyrus, as opposed to the basally swollen externo-dorsal rays of $H$. polygyrus, and is shared with the Polish material. The fourth species, $H$. asakawae [29] from Urumchi, in Western China, has expanded bases of the externo-dorsal rays, and was also originally described as $H$. polygyrus [30]; this appears to resemble $H$. polygyrus more closely than do the worms from Polish $A$. agrarius, but no molecular sequences are available. $H$. neopolygyrus has been documented on several occasions from the Asian mainland, as far west as Novosibirsk in Russia [31], and a detailed re-description was provided by Massoni et al. [32] based on material from Sichuan. In each case the filiform externo-dorsal rays have been highlighted as the specific character differentiating $H$. neopolygyrus from $H$. polygyrus. Furthermore, the original description of $H$. neopolygyrus highlights the small, flattened crêtes of this species, which do not increase in size to the ventral left-hand quadrant of the worm in the manner noted for $H$. polygyrus, but instead remain small and similar in size, a further character differentiating $H$. neopolygyrus from $H$. polygyrus and shared with the worms collected from Poland (Figure 1). The morphological description of $H$. neopolygyrus from Novosibirsk [31] is serendipitous because the $c y t b$ sequence for a Heligmosomoides isolate from A. uralensis in Novosibirsk (AM408303) is closely similar to those from our material, and also to those from Polish A. agrarius sequenced by Nieberding et al. [10]. Given the morphological and molecular agreement of the Polish worms with material from Novosibirsk, we identify the worms from A. agrarius in central Europe as $H$. neopolygyrus. The distribution of $A$. agrarius in Eurasia is discontinuous, with an eastern range centering on Eastern China and the Japanese islands, and a western range, extending from western China to central Europe. These two areas of distribution are separated by the Tibetan plateau. Should the molecular identity of $H$. neopolygyrus from Hokkaido be found to be different to that of specimens from Novosibirsk or the present material, the western form would require description as a new species; however, for the present we consider this to be unjustified, and consider these specimens to belong to $H$. neopolygyrus.

The genetic distance between $H$. polygyrus and $H$. neopolygyrus from Polish $A$. agrarius is considerable. At both ribosomal and mitochondrial loci, $H$. neopolygrus is much more closely associated with Heligmosomum, and it is clear from the phylogenies in Figure 2 that Heligmosomoides as a genus is paraphyletic, including both Heligmosomum and Ohbayashinema. Conventional 
wisdom based on morphology suggests a) that $H$. neopolygyrus and $H$. polygyrus are sister terminal clades [33,34]; b) that the Apodemus-infecting species are derived by host shifts from forms infecting voles [24,34,35]; and c) that the slender, coiled Heligmosomoides habitus is derived relative to the straight and stout Heligmosomum habitus. This latter assumption was implicit in Durette-Desset's [23] resurrection of the genus Heligmosomoides Hall, 1916 to accommodate the spirally coiled forms; Heligmosomum Railliet and Henry, 1909 is the older genus, and transfer of the spirally coiled forms to the younger genus Heligmosomoides implies that these are derived. The hypothesis that forms of Heligmosomoides in Apodemus are ancestral to those in microtine voles deserves consideration as a more parsimonious explanation of observed data than the derivation of mouse-infecting forms from those associated with microtines suggested by Durette-Desset [34]. In the first place, Apodemus is one of the older murid genera, extending back to a mid-Miocene (10 MYA) origin [36,37]. Arvicolid rodents, on the other hand, are a more recent group, and the diversification of Microtus and Myodes, the principal arvicolid hosts of heligmosomids did not occur until probably 2-3 MYA [38,39]. The Eastern Asian subgenus Apodemus (e.g. A. agrarius, A. latronum, A. peninsulae, A. draco) had separated from the Western Asian/European subgenus Sylvaemus (including A. sylvaticus, A. flavicollis, A. microps and A. mystacinus) by 8MYA [36], and the Eastern Asian group had diversified by c. 6MYA to give rise to the progenitors of modern $A$. agrarius and $A$. peninsulae [36]. It would seem reasonable to hypothesise that $H$. polygyrus and $H$. neopolygyrus arose in Sylvaemus (Western) and Apodemus (Eastern) respectively, and that these Heligmosomoides species have been distinct for c. 8 MYA.

The western migration of $A$. agrarius which brought $H$. neopolygrus into Central Europe has been rapid. Although there are reports of fossil $A$. agrarius from southern France from 17000 years BP [40], it is generally thought that the species was extinct in Europe following the last ice age, and that it has recolonised central Europe within the last few thousand years [41-43]. The earliest fossils in Poland date to c. 1000 years BP [42], and dating of hantavirus divergence suggests that the species acquired Saarema virus from A. flavicollis no more than 1000 years ago [41]. The recent importation of other pathogens into western Europe with this host has also been noted; Hildebrand et al. [44] record a range of unusual Bartonella genotypes in $A$. agrarius, including some most closely related to Far Eastern isolates. The extent of the secondary zone of contact between $H$. neopolygyrus and $H$. polygyrus is unclear. In Poland, the two species occur sympatrically, albeit separated by host identity, and to some extent by habitat preference; $H$. neopolygyrus was collected from $A$. agrarius at Wrocław where A. flavicollis sympatrically harboured $H$. polygyrus. A single worm sequenced by Nieberding et al. [10] but collected from $A$. flavicollis carried the $H$. neopolygyrus $c y t b$ sequence; some contact between $H$. polygyrus and $H$. neopolygyrus in eastern Europe may therefore be possible. Conversely, at the eastern limit of the range of $A$. agrarius, $H$. polygyrus-like worms were collected from $A$. microps [30] (now considered a synonym of $A$. uralensis [45]) in Urumchi, western China. This species seems able to act as a host for both $H$. polygyrus and $H$. neopolygyrus [10], and its role in maintaining the sympatry between the two Heligmosomoides species in Central Europe should be investigated further. Indeed, there are many records of $H$. polygyrus from rodents in Western Russia and the Caucasus (e.g. [46]), which should be reevaluated in the light of the present description of $H$. neopolygyrus from central Europe. We would predict that $H$. neopolygyrus and $H$. polygyrus have been separated for sufficiently long that they cannot interbreed; however, given that Caenorhabditis species have been shown to produce viable hybrids [47] across genetic distances similar to those recorded in the present study between $H$. neopolygyrus and $H$. polygyrus, this prediction should be tested experimentally.

Finally, the present study casts new light in the debate over the specific status of the laboratory model, $H$. bakeri. Behnke \& Harris [6] highlighted the similarity of $H$. bakeri and $H$. polygyrus corsicum at nuclear and mitochondrial loci. In that paper [6], the $H$. polygyrus corsicum sequences were based on a 'composite worm' and the present work has confirmed the molecular identity in one individual at multiple loci. As presented by Nieberding et al. [10], H. p. corsicum was a clade within $H$. polygyrus, despite its distinctness at both mitochondrial and nuclear loci $[5,6]$, and despite the fact that it had previously been raised to an independent species [29]. It is clear from the present work that this inclusion of $H$. polygyrus corsicum within $H$. polygyrus was due to over-reliance on a paradigm that Heligmosomoides in Apodemus represents a single panmictic species [10], making a study of their divergence an exercise in population genetics rather than in taxonomy. The Nieberding et al. [10] 'clade 4' represents the eastern $H$. neopolygyrus rather than $H$. polygyrus, and there is no need to invoke a central European refugium for this clade; it was brought to Europe with the host mouse after the LGM. It is also clear from the present work that $H$. bakeri/H. p. corsicum is the sister group to $H$. p. polygyrus. From a phyletic perspective this does not confirm the specific status of the two forms, but it certainly rejects the null hypothesis that they form part of a single terminal clade. Further progress in establishing the separate identity of $H$. bakeri depends on a critical evaluation of the taxonomy of Heligmosomoides from Apodemus and Mus across the region from the Carpathians (the eastern limit 
of Nieberding's detailed sampling) to western China, paying particular attention to such areas of high biodiversity as the Caucasus. Given the highly specific nature of the interference with the host immune system achieved by $H$. bakeri $[3,4,48]$ and $H$. polygyrus [1,2], such a study might be an especially fruitful approach to identifying the factors responsible for speciation and host specificity of these important GI nematodes.

\section{Conclusions}

1. Heligmosomoides neopolygyrus is recorded for the first time in Europe, arriving as a natural immigrant with Apodemus agrarius.

2. According to molecular criteria $H$. neopolygyrus and $H$. polygyrus are not closely related, and $H$. neopolygyrus may be more closely related to vole-infecting forms.

3. The vole-infecting genus Heligmosomum and the pika-infecting Ohbayashinema cluster within Heligmosomoides.

4. H. bakeri (the laboratory model) and H. p. corsicum are confirmed as the sister group to $H$. polygyrus, rather than representing an internal clade within the latter species.

\section{Additional file}

Additional file 1: ITS2 modelling to improve phylogenetic alignment.

\section{Competing interests}

The authors declare that they have no competing interests.

\section{Authors' contributions}

Molecular analyses carried out by GZ, APH and PDH in Oslo; alignments and phylogenetic analyses by APH and PDH. Morphological work and collection of material in Wrocław by GZ and JH. PDH and JMB conceived the study, MS drafted by PDH with help from GZ, APH and JMB. All authors have read and approved the final manuscript.

\section{Acknowledgements}

Support from Zoologica Scripta/Norwegian Research Council for GZ to work in Oslo, and support from the University of Oslo publication fund is gratefully acknowledged. Collection of material in Poland was generously supported by a grant from the Research Council of Poland to $\mathrm{JH}$. We thank all who have provided us with heligmosomid material over the years, including lan Montgomery (Belfast) for the Kildare worms and Voitto Haukisalmi (Finland) for the Turkish H. p. corsicum material. PDH would especially like to thank Mrs. Katarzyna Pajer at the University of Wrocław, for her master class in methacrylate section cutting.

\section{Author details}

${ }^{1}$ Department of Invertebrate Systematics and Ecology, Institute of Biology, Wrocław University of Environmental and Life Sciences, ul. Kożuchowska 5b, 51-631 Wrocław, Poland. 'Department of Parasitology, Institute of Genetics and Microbiology, University of Wrocław, ul. Przybyszewskiego 63, 51-148 Wrocław, Poland. ${ }^{3} \mathrm{KIT}$ Biomedical Research, Royal Tropical Institute, Meibergdreef 39, 1105 AZ, Amsterdam, the Netherlands. ${ }^{4}$ School of Life Sciences, University of Nottingham, NG2 7RD Nottingham, UK. ${ }^{5}$ Natural History Museum, University of Oslo, P.O. Box 1172, N-0562 Oslo, Norway.

Received: 26 February 2014 Accepted: 20 September 2014 Published online: 11 October 2014

\section{References}

1. Behnke JM, Eira C, Rogan M, Gilbert FS, Torres J, Miquel J, Lewis JW: Helminth species richness in wild wood mice, Apodemus sylvaticus, is enhanced by the presence of the intestinal nematode Heligmosomoides polygyrus. Parasitology 2009, 136:793-804.

2. Jackson JA, Friberg IM, Bolch L, Lowe A, Ralli C, Harris PD, Behnke JM, Bradley JE: Immunomodulatory parasites and toll-like receptor-mediated tumour necrosis factor alpha responsiveness in wild mammals. BMC Biol 2009, 7:16.

3. Hewitson JP, Grainger JR, Maizels RM: Helminth immunoregulation: The role of parasite secreted proteins in modulating host immunity. Mol Biochem Parasitol 2009, 167:1-11.

4. Maizels RM, Hewitson JP, Murray J, Harcus YM, Dayer B, Filbey KJ, Grainger JR, McSorley HJ, Reynolds LA, Smith KA: Immune modulation and modulators in Heligomosomoides polygyrus infection. Exp Parasitol 2012, 132:76-89.

5. Cable J, Harris PD, Lewis JW, Behnke JM: Molecular evidence that Heligmosomoides polygyrus from laboratory mice and wood mice are separate species. Parasitology 2006, 133:111-122.

6. Behnke JM, Harris PD: Heligmosomoides bakeri: a new name for an old worm? Trends Parasitol 2010, 26:524-529.

7. Maizels RM, Hewitson JP, Gause WC: Heligmosomoides polygyrus: one species still. Trends Parasitol 2011, 27:100-101.

8. Dujardin F: Historie naturelle des Helminthes ou vers intestinaux; 1845. Paris, Libraire encyclopedique de Roret.

9. Nieberding C, Libois R, Douady CJ, Morand S, Michaux JR: Phylogeography of a nematode (Heligmosomoides polygyrus) in the western Palearctic region: persistence of northern cryptic populations during ice ages? Mol Ecol 2005, 14:765-779.

10. Nieberding CM, Durette-Desset MC, Vanderpoorten A, Casanova JC, Ribas A, Deffontaine V, Feliu C, Morand S, Libois R, Michaux JR: Geography and host biogeography matter for understanding the phylogeography of a parasite. Mol Phylogenet Evol 2008, 47:538-554.

11. Nieberding C, Morand S, Libois R, Michaux JR: Parasites and the island syndrome: the colonisation of the western Mediterranean islands by Heligmosomoides polygyrus (Dujardin, 1845). J Biogeogr 2006, 33:1212-1222.

12. Khrustalev AV, Hoberg EP: Silver staining for elucidation of the synlophe in trichostrongyle nematodes. J Parasitol 1995, 81:1016-1018.

13. Anderson TJC: Ascaris infections in humans from North America: molecular evidence for cross infection. Parasitology 1995, 110:215-219.

14. Chilton NB, Gasser RB, Beveridge I: Phylogenetic relationships of Australian strongyloid nematodes inferred from ribosomal DNA sequence data. Int J Parasitol 1997, 27:1481-1494.

15. Okamoto M, Urushima $\mathrm{H}$, Hasegawa H: Phylogenetic relationships of rodent pinworms (genus Syphacia) in Japan inferred from 28S rDNA sequences. Parasitol Int 2009, 58:330-333.

16. Tamura K, Peterson D, Peterson N, Stecher G, Nei M, Kumar S: MEGA5: Molecular Evolutionary Genetics Analysis using Maximum Likelihood, Evolutionary Distance, and Maximum Parsimony Methods. Mol Biol Evol 2011, 28:2731-2739.

17. Stamatakis A: RAxML version 8: A tool for phylogenetic analysis and post-analysis of large phylogenies. Bioinformatics 2014, 1-2. doi:10.1093/ bioinformatics/btu033.

18. Miller MA, Pfeiffer W, Schwartz T: Creating the CIPRES science gateway for inference of large phylogenetic trees. New Orleans, LA: Gateway Computing Environments Workshop (GCE); 2010:1-8.

19. Durette-Desset MC: Ohbayashinema ochotoni n. gen, n. sp. (Nematoda, Trichostrongyloidea), parasite d'un lagomorphe du Nepal. Interet phyletique de ce genre. Bull Mus Natl Hist Nat 1974, 144:415-418.

20. Gouy De Bellocq J, Ferte H, Depaquit J, Justine J-L, Tillier A, Durette-Desset MC: Phylogeny of the Trichostrongylina (Nematoda) inferred from $28 \mathrm{~S}$ rDNA sequences. Mol Phy Ev 2001, 19:430-442.

21. Koetschan C, Forster F, Keller A, Schleicher T, Ruderisch B, Schwarz R, Muller T Wolf M, Schulz J: The ITS2 database III - sequences and structures for phylogeny. Nucleic Acids Res 2010, 38:275-279.

22. Chilton NB, Hoste H, Newton LA, Beveridge I, Gasser RB: Common secondary structures for the second internal transcribed spacer pre-rRNA of two subfamilies of trichostrongylid nematodes. Int J Parasitol 1998, 28:1765-1773.

23. Durette-Desset MC: Les systèmes d'arêtes cuticulaires chez les Nématodes Héligmosomes. III. Etude de sept espèces parasites de 
rongeurs néarctiques et rétablissement du genre Heligmosomoides Hall, 1916. Bull Mus Natl Hist Nat 1968, 40:186-209.

24. Durette-Desset MC: Essai de classification des nématodes Héligmosomes. Corrélations avec la Paléobiogéographie des hôtes. Mém Mus Natl Hist Nat Zool 1971, 69:1-126.

25. Durette-Desset MC: Identification des strongyles des Mulot et Campagnols décrits par Dujardin. Ann Parasitol Hum Comp 1968, 43:387-404.

26. Tenora F, Barus V, Hildebrand J, Prokes M: Species of the genus Heligmosomum Railliet et Henry, 1909 (Nematoda, Heligmosominae) parasitizing Rodentia in Europe. Acta Univ Agric Silvic Mendelianae Brun 2002, 5:7-13.

27. Asakawa M, Ohbayashi M: Genus Heligmosomoides Hall, 1916 (Heligmosomidae: Nematoda) from the Japanese wood mice, Apodemus spp. I. A Taxonomical study on four taxa of the genus Heligmosomoides from three species of the Japanese Apodemus sp. J Coll Dairy 1986, 11:317-331.

28. Chabaud AG, Rausch RL, Desset MC: Nématodes parasites de Rongeurs et Insectivores japonais. Bull Soc Zool France 1963, 88:489-512.

29. Tenora F, Barus V: Synonymy of the nematode Heligmosomoides polygyrus (Heligmosomidae) and notes on validity of related species. Helminthologia 2001, 38:176-177.

30. Asakawa M, Tenora F, Hasegawa H, Jin ML, He XQ, Wu XM, Tsuchiya N Moriwaki K, Fukimoto SI, Ohbayashi M: Heligmosomoides polygyrus (Dujardin, 1845) (Nematoda, Trichostongyloidea, Heligmosomidae) from Apodemus microps (Rodentia, Muridae) in Ulumuchi, China. Bull Biogeogr Soc Japan 1992, 47:69-71.

31. Asakawa M, Oda SI, Harada M, Narita Y, Koyasu K, Chechulin Al, Dobrotvorsky AK, Panov W, Borodin PM, Fedrov KP: Heligmosomid nematodes from the small mammals captured in the adjacent area of Akademgorodok city, southern part of West Siberia, Russia. Bull Biogeogr Soc Japan 1995, 50:11-14.

32. Massoni J, Durette-Desset MC, Quéré JP, Audebert F: Redescription of Heligmosomoides neopolygyrus Asakawa \& Ohbayashi, 1986 (Nematoda: Heligmosomidae) from a chinese rodent, Apodemus peninsulae (Rodentia, Muridae) with comments on Heligmosomoides polygyrus polygyrus (Dujardin, 1845) and related species in China and Japan. Parasite 2012, 19:367-374.

33. Asakawa M: Genus Heligmosomoides Hall, 1916 (Heligmosomidae: Nematoda) from Japanese wood mice, Apodemus spp. J Coll Dairy 1988, 12:349-365

34. Durette-Desset MC: Evolution des nematodes heligmosomes en rapport avec celle de leurs hotes fondamenteaux, les Microtidae. C R Acad Sci D 1967, 265:1500-1503.

35. Asakawa M: Genus Heligmosomoides Hall, 1916 (Heligmosomidae: Nematoda) from Japanese islands. Helminthologia 1991, 28:155-163.

36. Michaux JR, Chevret P, Filippucci MG, Macholan M: Phylogeny of the genus Apodemus with a special emphasis on the subgenus Sylvaemus using the nuclear IRBP gene and two mitochondrial markers: cytochrome $b$ and 12 S rRNA. Mol Phylogenet Evol 2002, 23:123-136.

37. Fabre PH, Hautier L, Dimitrov D, Douzery EJP: A glimpse on the pattern of rodent diversification: a phylogenetic approach. BMC Evol Biol 2012, 12:88.

38. Cook JA, Runck AM, Conroy CJ: Historical biogeography at the crossroads of the northern continents: molecular phylogenetics of red-backed voles (Rodentia:Arvicolidae). Mol Phylogenet Evol 2004, 30:767-777.

39. Jaarola M, Martinkova N, Gunduz I, Brunhoff C, Zima J, Nadachowski A, Amori G, Bulatova NS, Chondropoulos B, Fraguedakis-Solis S, GonzalezEsteban J, Lopez-Fuster MJ, Kandaurov AS, Kefelioglu H, Da Luz Mathias M, Villate I, Searle JB: Molecular phylogeny of the speciose vole genus Microtus (Arvicolinae, Rodentia) inferred from mitochondrial DNA sequences. Mol Phylogenet Evol 2004, 33:647-663.

40. Aguilar JP, Pelissie T, Sige B, Michaux J: Occurrence of the striped field mouse lineage (Apodemus agrarius Pallas, 1771; Rodentia; Mammalia) in the late Pleistocene of southern France. C R Palevol 2008, 7:217-225.

41. Lin XD, Wang W, Gou WP, Zhang XH, Xing JG, Chen SZ, Li MH, Chen Y, Xu J, Plyusnin A, Zhang YZ: Cross-species transmission in the speciation of the currently known Murinae-associated hantaviruses. J Virol 2012, 86:11171-11182.

42. Kowalski K: Pleistocene rodents of Europe. Folia Quat 2001, 12:3-389

43. Toskan B, Krystufek B: Noteworthy rodent records from the Upper Pleistocene and Holocene of Slovenia. Mammalia 2006, 70:98-105
44. Hildebrand J, Paziewska-Harris A, Zaleśny G, Harris PD: PCR characterisation suggests an unusual range of Bartonella species infect the striped field mouse Apodemus agrarius in Central Europe. Appl Environ Microbiol 2013, 79:5082-5084.

45. Musser GG, Carleton MD: Superfamily Muroidea. In Mammal species of the World, a taxonomic and geographic reference. 3rd edition. Edited by Wilson DE, Reeder DM. Baltimore: The John Hopkins University Press; 2005:894-1531.

46. Schultz RS: Zur kenntnis der Helminthenfauna der Nagetiere der Union S.S.R. I. Subordo Strongylata: 1. Fam. Trichostrongylidae Leiper, 1912. Trud Gosudarstv Inst Exp Vet 1926, 4:5-32.

47. Kiontke KC, Felix MA, Ailion M, Rockman MV, Braendle C, Penigault JB, Fitch DHA: A phylogeny and molecular barcodes for Caenorhabditis, with numerous new species from rotting fruits. BMC Evol Biol 2011, 11:339.

48. Behnke JM, Hannah J, Pritchard DI: Nematospiroides dubius in the mouse: evidence that adult worms depress the expression of homologous immunity. Parasite Immunol 1983, 5:397-408.

doi:10.1186/s13071-014-0457-y

Cite this article as: Zaleśny et al:: Heligmosomoides neopolygyrus Asakawa \& Ohbayashi, 1986, a cryptic Asian nematode infecting the striped field mouse Apodemus agrarius in Central Europe. Parasites \& Vectors 2014 7:457.

\section{Submit your next manuscript to BioMed Central and take full advantage of:}

- Convenient online submission

- Thorough peer review

- No space constraints or color figure charges

- Immediate publication on acceptance

- Inclusion in PubMed, CAS, Scopus and Google Scholar

- Research which is freely available for redistribution 